EDITORIAL
pISSN 2234-778X • elSSN 2234-5248
J Minim Invasive Surg 2020;23(2):63-64

\title{
Percutaneous Internal Ring Suturing for Indirect Inguinal Hernia in Pediatric Patients
}

\author{
Hye Kyung Chang, M.D., Ph.D. \\ Department of Surgery, College of Medicine, Kyung Hee University, Seoul, Korea
}

\begin{abstract}
Many laparoscopic techniques have been developed to repair inguinal hernia in children using either an intraperitoneal or extraperitoneal approach. Percutaneous internal ring suturing (PIRS) is one of the extracorporeal suture techniques. It could be performed with comparable surgical complication or recurrence rates and excellent cosmetic results. To minimize the perioperative complications, surgical procedures of PIRS can be performed carefully with technical refinements for inguinal hernia repair in children.
\end{abstract}

Keywords: Inguinal hernia, Pediatrics, Laparoscopy, Recurrence, Suture techniques, Inguinal ring

\author{
Received May 18, 2020 \\ Accepted May 26, 2020 \\ Corresponding author \\ Hye Kyung Chang \\ Department of Surgery, Kyung Hee \\ University Hospital, 26 Kyunghee- \\ daero, Dongdaemun-gu, Seoul \\ 02447, Korea \\ Tel: +82-2-958-9506 \\ Fax: +82-2-958-9507 \\ E-mail: ksels2010@gmail.com \\ ORCID: \\ https://orcid.org/0000-0003-2537-7464
}

Copyright @ 2020 The Journal of Minimally Invasive Surgery. All rights reserved.

This is an Open Access article distributed under the terms of the Creative Commons Attribution Non-Commercial License (http:/ creativecommons.org/licenses/by-nc/4.0/) which permits unrestricted non-commercial use, distribution, and reproduction in any medium, provided the original work is properly cited.

Many laparoscopic techniques have been developed to repair inguinal hernia in children with improved outcomes. There are two categories of laparoscopic suture techniques according to the suturing procedures of internal inguinal ring: extracorporeal or intracorporeal suturing and knotting. Percutaneous internal ring suturing (PIRS) is one of the extracorporeal suture techniques. By extracorporeal suturing and knotting technique, the surgical procedure of inguinal hernia repair could be simple without requiring difficult laparoscopic suturing and knotting skills. Because of the easy extracorporeal suturing and knotting techniques, operative time is short. Moreover, it could be performed with comparable surgical complication or recurrence rates and excellent cosmetic results. ${ }^{1,2}$

To prevent surgical complications or recurrences, selection of the suturing material could be critical., ${ }^{2,3}$ Because of the more tissues included in the loop of suture in the extracorpo- real techniques rather than in the intracorporeal techniques, using tense suture material is important to make a secure suture especially in the obese children with relatively thick abdominal wall. However, too heavy suture materials could be complicated with stitch abscess or granuloma.

In spite of the easy and feasible techniques, there are a few technical limitations of the extracorporeal suturing and knotting technique in the treatment of inguinal hernia in children. One of the limitations in the application of the PIRS could be complicated hydrocele with many septations in the sac and very small communicating internal inguinal ring. ${ }^{4}$ It could be hard to managing the complicated hydrocele only by PIRS without decompressing the hydrocele. Another limitation could be the incarcerated or strangulated hernia. In the treatment of incarcerated or even strangulated inguinal hernia, if the incarcerated organs were not reducible manually, PIRS is not applicable. 
Bleeding is the main complication of PIRS in the presented study group resulting $12 \%$ of complicating rate. Intraoperative vessel injury can be resulted by blind puncture of the needle with sharp tip or limited action of the needle in the narrow space. It can be worsen to uncontrollable bleeding or large hematoma by injury of the vessels, resulting poor vision of surgical field or conversion to open surgery, ${ }^{5}$ and complicated postoperatively to wound infection or recurrence. Technical adjustments as using the safe needle, one-puncture technique or dissection with saline are required to prevent the uncontrollable bleeding during the procedures. ${ }^{6}$

\section{ORCID}

Hye Kyung Chang, https://orcid.org/0000-0003-2537-7464

\section{CONFLICT OF INTEREST}

None.

\section{FUNDING}

None.

\section{ACKNOWLEDGMENTS}

None.

\section{REFERENCES}

1) Shalaby R, Ismail M, Dorgham A, et al. Laparoscopic hernia repair in infancy and childhood: evaluation of 2 different techniques. J Pediatr Surg 2010;45:2210-2216.

2) Takehara H, Yakabe S, Kameoka K. Laparoscopic percutaneous extraperitoneal closure for inguinal hernia in children: clinical outcome of 972 repairs done in 3 pediatric surgical institutions. J Pediatr Surg 2006;41:1999-2003.

3) Ozgediz D, Roayaie K, Lee $H$, et al. Subcutaneous endoscopically assisted ligation (SEAL) of the internal ring for repair of inguinal hernias in children: report of a new technique and early results. Surg Endosc 2007;21:1327-1331.

4) Prasad R, Lovvorn HN, 3rd, Wadie GM, Lobe TE. Early experience with needleoscopic inguinal herniorrhaphy in children. J Pediatr Surg 2003;38:1055-1058.

5) Korkmaz M, Güvenç BH. Comparison of Single-Port Percutaneous Extraperitoneal Repair and Three-Port Mini-Laparoscopic Repair for Pediatric Inguinal Hernia. J Laparoendosc Adv Surg Tech A 2018;28:337-342.

6) Thomas DT, Göcmen KB, Tulgar S, Boga I. Percutaneous internal ring suturing is a safe and effective method for the minimal invasive treatment of pediatric inguinal hernia: Experience with 250 cases. J Pediatr Surg 2016;51:1330-1335. 